\title{
Recombinant factor VIIa affects anastomotic patency of vascular grafts in a rabbit model
}

\author{
C. David Mazer, MD, FRCPC, ${ }^{\text {a,c,e }}$ Howard Leong-Poi, MD, FRCPC, ${ }^{\text {bee }}$ Tejinder Chhina, MD, FRCPC, ${ }^{\text {a }}$ \\ Zuhair Alfardan, MD, ${ }^{\mathrm{d}}$ Harry Lapierre, MD, FRCSC, ${ }^{\mathrm{d}}$ Zhilan Wang, MSc, ${ }^{\mathrm{a}, \mathrm{e}}$ \\ Zane S. Jackson, MD, PhD, ${ }^{\mathrm{d}}$ Beiping Qiang, MD ${ }^{\mathrm{f}}$ James Mahoney, MD, FRCSC, ${ }^{\text {d,e }}$ \\ David Latter, MD, FRCSC, ${ }^{\text {d,e }}$ Gregory M. T. Hare, MD, PhD, FRCPC,, ,c,e \\ Bradley H. Strauss, MD, FRCPC, ${ }^{\text {,e,f }}$ and Jerome Teitel, MD, FRCPC ${ }^{\text {be }}$
}

\begin{abstract}
Objective: Recombinant factor VIIa can decrease postoperative bleeding after cardiac surgery. However, the potential for recombinant factor VIIa to cause early vascular graft occlusion at the site of new vascular anastomoses has not been fully explored. We hypothesized that recombinant factor VIIa would cause a dose-dependent reduction in vascular graft patency in rabbits.
\end{abstract}

\begin{abstract}
Methods: Reversed end-to-end interpositional vein grafts were sutured into the carotid artery of heparinized rabbits, and then recombinant factor VIIa (300 $\mu \mathrm{g} / \mathrm{kg}, 90 \mu \mathrm{g} / \mathrm{kg}$, or $20 \mu \mathrm{g} / \mathrm{kg}$ intravenously) or placebo was administered ( $\mathrm{n}=16$ /group). Graft patency was assessed at 24 hours using a vascular ultrasound probe. Factor VII activity levels were measured using a prothrombin time-based assay. In different rabbits, the patency of venous end-to-side anastomoses and simple carotid arterial repairs was assessed (recombinant factor VIIa, $300 \mu \mathrm{g} / \mathrm{kg}$ vs placebo, $\mathrm{n}=8 /$ group). Data were analyzed using Fisher's exact test, $t$ tests, or analysis of variance.
\end{abstract}

\begin{abstract}
Results: Physiologic variables (activated clotting time, hemoglobin, $\mathrm{pH}, \mathrm{PaO}_{2}$ ) and vessel diameter were not different between groups. Vein graft patency was reduced $(93.8 \%, 81.2 \%, 13.8 \%$, and $6.3 \%)$ as factor VII activity levels increased $(1.8 \pm 0.4,4.4 \pm 2.1,11.8 \pm 4.7$, and $23.6 \pm 16.9 \mathrm{U} / \mathrm{mL}$, respectively) with increasing doses of recombinant factor VIIa administered $(0,20,90$, and $300 \mu \mathrm{g} / \mathrm{kg}$, respectively, $P<.05)$. Patency in the arterial repairs and end-to-side venous grafts was also reduced in recombinant factor VIIa-treated rabbits $(P<.05$ for both).
\end{abstract}

Conclusions: This study suggests that recombinant factor VIIa is associated with a dose-dependent increase in fresh vascular graft occlusion. Higher doses of recombinant factor VIIa may be associated with increased thrombotic outcomes. (J Thorac Cardiovasc Surg 2011;142:418-23)

Coronary artery bypass graft surgery is commonly performed to provide myocardial revascularization through arterial and venous bypass grafts. Postoperative hemorrhage occurs in up to $20 \%$ of these patients and has been associated with increased morbidity and mortality. Clinical management of postoperative bleeding includes multimodal therapeutic strategies with antifibrinolytics, cell salvage, and transfusion

\footnotetext{
From the Departments of Anesthesia, ${ }^{\mathrm{a}}$ Medicine, ${ }^{\mathrm{b}}$ Physiology, ${ }^{\mathrm{c}}$ and Surgery, ${ }^{\mathrm{d}}$ University of Toronto, Ontario, Canada; Keenan Research Centre in the Li Ka Shing Knowledge Institute, ${ }^{\mathrm{e}}$ St Michael's Hospital, Toronto, Ontario, Canada; and Sunnybrook Health Sciences Center, ${ }^{f}$ University of Toronto, Ontario, Canada. Supported in part by a grant from Physicians' Services Incorporated.

Disclosures: Dr Mazer has received honoraria from AstraZeneca, NovoNordisk, Abbott Laboratories, and Oxygen Biotherapeutics; Dr Teitel has received honoraria from Baxter International, Wyeth, CSL Behring, and NovoNordisk Canada. Received for publication Oct 14, 2009; revisions received Oct 3, 2010; accepted for publication Nov 14, 2010; available ahead of print Jan 31, 2011.

Address for reprints: C. David Mazer, MD, FRCPC, Department of Anesthesia, St Michael's Hospital, 30 Bond Street, Toronto, ON, Canada M5B 1W8 (E-mail: mazerd@smh.ca).

$0022-5223 / \$ 36.00$

Copyright (c) 2010 by The American Association for Thoracic Surgery doi:10.1016/j.jtcvs.2010.11.020
}

of allogeneic red blood cells, platelets, and coagulation factors. However, each of these therapies has been associated with significant risks and complications. A treatment that promotes hemostasis without compromising patency would be a valuable addition to current clinical practice. Recombinant factor VIIa (rFVIIa) is an approved therapy for treatment for bleeding episodes in patients with hemophilia, which has recently been used off-label to treat refractory bleeding in patients undergoing cardiac surgery. ${ }^{1-5}$ The profound hemostatic effect of rFVIIa is thought to be a function of site-specific thrombin generation by tissue factor-mediated activation of coagulation or by tissue factor-independent thrombin generation on activated platelets at sites of vascular injury. ${ }^{6}$ Although an increasing number of reports have described the successful use of rFVIIa to treat bleeding after cardiac surgery, the safety and efficacy of this treatment have not been well studied. This is of particular importance in patients with cardiovascular disease with fresh vascular anastomoses. The potential hemostatic benefits of rFVIIa could be negated if tissue factor expression and thrombin generation at the site of new anastomoses resulted in graft narrowing or 


\section{Abbreviations and Acronyms \\ $\mathrm{ACT}=$ activated clotting time \\ rFVIIa $=$ recombinant factor VIIa}

thrombosis. Recent concerns of thrombotic complications with aprotinin and erythropoietin emphasize the importance of properly evaluating hemostatic drugs before widespread clinical use. ${ }^{7-9}$ This study was designed to test the hypothesis that the administration of rFVIIa reduces graft patency at the site of new vascular anastomoses in a dosedependent fashion, using a rabbit model.

\section{MATERIALS AND METHODS}

\section{Animal Model and Surgical Preparation}

All animal protocols were approved by the Animal Care and Use Committee at St Michael's Hospital in accordance with the requirements of Canadian Animal Care Committee. New Zealand White rabbits (3-4kg) were premedicated with ketamine $(10 \mathrm{mg} / \mathrm{kg})$ and xylazine $(2 \mathrm{mg} / \mathrm{kg})$, and anesthetized with $1 \%$ to $3 \%$ isoflurane in oxygen delivered via face mask and spontaneous ventilation. Body temperature was maintained using radiant warming lamps. The ear artery was cannulated with a $25 \mathrm{G}$ catheter for direct blood pressure measurement and blood sampling for blood gas analysis and measurement of hemoglobin concentration using co-oximetry (Radiometer ALB 500 and OSM 3, London Scientific, London, Canada). An ear vein was cannulated with a $22-\mathrm{g}$ catheter for administration of study drug or saline vehicle. Intravenous isotonic saline was administered continuously at approximately $2 \mathrm{~mL} / \mathrm{kg} / \mathrm{h}$ throughout surgery to replace insensible fluid losses.

Through a midline neck incision, the right carotid artery was isolated and dissected free. A 2- to 3-cm portion of the ipsilateral jugular vein was then isolated, excised, and flushed with heparinized saline. The animals were then systemically anticoagulated with heparin (250-300 IU/kg intravenously) to achieve and maintain a target activated clotting time (ACT) of greater than 250 seconds during carotid occlusion and graft suturing. One of 2 experimental protocols was then performed, as outlined below. All anastomoses were performed with interrupted 9-0 Prolene sutures (AROSurgical, Newport Beach, Calif). Surgical hemostasis and graft patency were always ensured by inspection before wound closure. The isoflurane was then discontinued, and the animals were allowed to recover.

\section{Experimental Protocol 1: Recombinant Factor VIIa Dose Response}

In protocol 1, an interpositional graft of reversed jugular vein was fashioned in the carotid artery using 2 artery-to-vein anastomoses. The animals then received rFVIIa (Niastase; NovoNordisk, Mississauga, Canada) or placebo ( $\mathrm{n}=16$ per group) in a blinded fashion, so that neither the person performing the anastomoses nor the person assessing the primary outcome was aware of treatment assignment. The study drug was prepared in accordance with the manufacturer's recommendations immediately before administration and injected intravenously via the ear vein. Three dosing regimens of rFVIIa were studied: 300,90 , and $20 \mu \mathrm{g} / \mathrm{kg}$. These regimens were chosen because they span the range of doses given to humans. The currently approved dose for hemophiliac patients is $90 \mu \mathrm{g} / \mathrm{kg}$. Before and approximately 20 minutes after drug (or placebo) administration, blood was drawn and centrifuged ( $3400 \mathrm{rpm} \times 12$ minutes), and citrated plasma was frozen at -80 degrees for subsequent measurement of factor VII activity levels (see below).

\section{Experimental Protocol 2: Effect of High-Dose Recombinant Factor VIIa on Arterial and End-to-Side Venous Anastomoses}

In protocol 2, 2 different anastomotic techniques were evaluated in the same animal. The right carotid artery was ligated at its midpoint, and the vein segment was used as a bypass graft rather than an interposition graft by creating 2 end-to-side anastomoses. In addition, the contralateral carotid artery was transected and then repaired with a single end-to-end arterial repair. The end-to-side vein graft anastomoses were performed to model a saphenous vein to coronary artery graft. The simple arterial repair was performed to model vascular grafts using arterial conduits. In this protocol, the highest dose of rFVIIa was used $(300 \mu \mathrm{g} / \mathrm{kg})$ to maximize the ability to detect potential differences in graft occlusion with different graft techniques.

\section{Outcomes/Measurements}

Primary outcome. The primary outcome of this study was graft occlusion at 1 day as assessed by ultrasound or direct visual inspection in rabbits anesthetized as described. The investigators performing the anastomoses or assessing the primary outcome were blinded to study treatment. An HDI 5000cv ultrasound system (Philips Ultrasound, Mississauga, Canada), equipped with a high-frequency $(15 \mathrm{MHz})$ linear array vascular probe (CL15-7), was used to visualize the body of the graft, including all anastomotic sites, using standard B-mode ultrasound in longitudinal and transverse axes. The grafts were defined as patent if there was demonstrable flow through them or there was no evidence of occlusion at autopsy. Filling defects representing intraluminal thrombi within the graft were identified and the dimensions were measured in 2 orthogonal planes. Blood flow through patent grafts was assessed using standard color and spectral Doppler techniques. Quantitative blood flow measurements were performed in the proximal and distal carotid arteries using standard quantitative volume flow techniques (HDI5000cv). This technique uses mean velocities and vessel diameters to calculate volumetric flow through vessels and has been validated. ${ }^{10}$

Factor VII activity levels in the citrated plasma samples were measured in the dose-response experiments using standard 1-stage coagulation endpoint techniques, with rabbit brain thromboplastin (IL Test PT-Fibrinogen HS; Instrumentation Laboratory, Bedford, Mass) and immunoadsorbed factor VII deficient plasma (Hemoliance Deficient Plasma; BeckmanCoulter Canada, Mississauga, Ontario, Canada). The calibration curve used reference plasma calibrated against the World Health Organization standard.

\section{Statistical Analyses}

Statistical analyses were performed using the SAS System for Windows, version 8.02 (SAS Institute Inc, Cary, NC). The sample size was estimated assuming a $95 \%$ patency rate in the placebo group based on previous studies, a $40 \%$ reduction with $\mathrm{rFVIIa}$, an alpha error of 0.05 , and a beta of 0.20 (power 0.80). The primary outcome was assessed using Fisher's exact test. Other data were analyzed with $t$ tests or 2-way analysis of variance for continuous variables as appropriate. When a significant F-ratio was present, multiple comparisons were made using Dunnett's and Tukey's tests. All data are reported as mean \pm standard deviation or frequency \pm $95 \%$ confidence intervals.

\section{RESULTS}

Fifteen of 95 rabbits entered into the protocol were excluded (surgical difficulties with anastomoses $[\mathrm{n}=10]$, perioperative death $[\mathrm{n}=2]$, problems with anticoagulation $[\mathrm{n}=2]$, and problems with data acquisition $[\mathrm{n}=1])$, leaving a total of 80 animals. Sixty-four rabbits were used in the 
TABLE 1. Physiologic variables

\begin{tabular}{|c|c|c|c|c|}
\hline Variable & Protocol group & rFVIIa dose & Baseline & Postheparin \\
\hline \multirow[t]{6}{*}{$\mathrm{ACT}$} & \multirow[t]{4}{*}{ Protocol 1} & $0 \mu / \mathrm{kg}$ (placebo) & $71 \pm 3$ & $282 \pm 90 *$ \\
\hline & & $20 \mu / \mathrm{kg}$ & $73 \pm 7$ & $318 \pm 66^{*}$ \\
\hline & & $90 \mu / \mathrm{kg}$ & $76 \pm 9$ & $268 \pm 91 *$ \\
\hline & & $300 \mu / \mathrm{kg}$ & $81 \pm 15$ & $329 \pm 93 *$ \\
\hline & \multirow[t]{2}{*}{ Protocol 2} & 0 & $96 \pm 20$ & $389 \pm 93 *$ \\
\hline & & 300 & $96 \pm 23$ & $379 \pm 51 *$ \\
\hline \multirow[t]{6}{*}{$\mathrm{Hb}$} & \multirow[t]{4}{*}{ Protocol 1} & $0 \mu / \mathrm{kg}$ (placebo) & $122 \pm 7$ & $115 \pm 12$ \\
\hline & & $20 \mu / \mathrm{kg}$ & $119 \pm 8$ & $113 \pm 9$ \\
\hline & & $90 \mu / \mathrm{kg}$ & $118 \pm 8$ & $117 \pm 8$ \\
\hline & & $300 \mu / \mathrm{kg}$ & $125 \pm 10$ & $121 \pm 8$ \\
\hline & \multirow[t]{2}{*}{ Protocol 2} & 0 & $108 \pm 9$ & $106 \pm 8$ \\
\hline & & 300 & $113 \pm 10$ & $110 \pm 12$ \\
\hline \multirow[t]{6}{*}{ MAP } & \multirow[t]{4}{*}{ Protocol 1} & $0 \mu / \mathrm{kg}$ (placebo) & $70 \pm 7$ & $64 \pm 8$ \\
\hline & & $20 \mu / \mathrm{kg}$ & $71 \pm 4$ & $62 \pm 9$ \\
\hline & & $90 \mu / \mathrm{kg}$ & $63 \pm 7 \dagger$ & $56 \pm 11 \dagger$ \\
\hline & & $300 \mu / \mathrm{kg}$ & $70 \pm 4$ & $63 \pm 4$ \\
\hline & \multirow[t]{2}{*}{ Protocol 2} & 0 & $67 \pm 7$ & $65 \pm 13$ \\
\hline & & 300 & $64 \pm 12$ & $66 \pm 17$ \\
\hline \multirow[t]{6}{*}{$\mathrm{pH}$} & \multirow[t]{4}{*}{ Protocol 1} & $0 \mu / \mathrm{kg}$ (placebo) & $7.38 \pm 0.04$ & $7.35 \pm 0.08$ \\
\hline & & $20 \mu / \mathrm{kg}$ & $7.34 \pm 0.04$ & $7.31 \pm 0.07$ \\
\hline & & $90 \mu / \mathrm{kg}$ & $7.36 \pm 0.06$ & $7.36 \pm 0.09$ \\
\hline & & $300 \mu / \mathrm{kg}$ & $7.35 \pm 0.04$ & $7.36 \pm 0.09$ \\
\hline & \multirow[t]{2}{*}{ Protocol 2} & 0 & $7.30 \pm 0.10$ & $7.28 \pm 0.13$ \\
\hline & & 300 & $7.33 \pm 0.09$ & $7.26 \pm 0.14$ \\
\hline \multirow[t]{6}{*}{$\mathrm{PaO}_{2}$} & \multirow[t]{4}{*}{ Protocol 1} & $0 \mu / \mathrm{kg}$ (placebo) & $433 \pm 45$ & $404 \pm 41$ \\
\hline & & $20 \mu / \mathrm{kg}$ & $429 \pm 55$ & $397 \pm 60$ \\
\hline & & $90 \mu / \mathrm{kg}$ & $401 \pm 79$ & $382 \pm 59$ \\
\hline & & $300 \mu / \mathrm{kg}$ & $452 \pm 34$ & $446 \pm 64$ \\
\hline & \multirow[t]{2}{*}{ Protocol 2} & 0 & $354 \pm 76$ & $359 \pm 85$ \\
\hline & & 300 & $379 \pm 68$ & $339 \pm 77$ \\
\hline
\end{tabular}

$r F V I I a$, Recombinant factor VIIa; $A C T$, activated clotting time; $H b$, hemoglobin $M A P$, mean arterial pressure. $* P<.05$ compared with baseline value. $\dagger P<.05$ compared with other groups at that time point.

experimental protocol $1(\mathrm{n}=16$ per dose $)$, and 16 animals were used in experimental protocol 2 ( $\mathrm{n}=8$ per group). The average weight of the rabbits was not different between groups $(3.8 \pm 0.5 \mathrm{~kg})$.

Protocol 1: Dose Response Protocol

Physiologic variables. There were no significant differences in baseline physiologic variables between groups
(Table 1). ACT was appropriately elevated in all groups after heparin administration. All groups experienced slight decreases in arterial pressures and decreased hemoglobin concentrations as a result of anesthesia and surgery. There were no differences between groups with the exception of a slightly reduced mean arterial pressure in the rFVIIa $90 \mu \mathrm{g} / \mathrm{kg}$ group (Table 1).

Graft patency and flow. The average diameter of the carotid arteries $(0.14 \pm 0.02 \mathrm{~cm})$ and vein grafts $(0.39 \pm 0.06 \mathrm{~cm})$ was similar between groups (Table 2). Graft patency (defined as number of grafts patent/total number of grafts*100) was highest in the placebo group and lowest in the rFVIIa $300 \mu \mathrm{g} / \mathrm{kg}$ group (Figure $1 ; 93.8 \%$ vs $6.3 \% ; \mathrm{P}<.05$ ). Patency in the 20 and $90 \mu \mathrm{g} / \mathrm{kg}$ dose groups was intermediate $(81.3 \%$ vs $43.8 \% ; \mathrm{P}<.05)$. At the time of visual inspection, the grafts were patent or occluded with thrombus, and in all cases the thromboses were confined to the anastomotic site; there was no evidence of thromboses in other vessels. When calculated as flow/total number grafts, flow was significantly reduced in the high-dose rFVIIa group, but when calculated as flow/ open graft, there were no significant differences between groups (Table 2).

Factor VII activity levels. There were no differences in factor VII activity levels between groups before drug (or placebo) administration (Figure 2). Factor VII activity levels increased significantly in a dose-dependent fashion in all groups after rFVIIa administration, with the highest levels in the $300 \mu \mathrm{g} / \mathrm{kg}$ group (Figure 2).

\section{Protocol 2: Bilateral Graft Protocol}

In the animals undergoing bilateral anastomoses $(\mathrm{n}=8$ animals per group), there were no significant differences between the placebo and the rFVIIa $300 \mu \mathrm{g} / \mathrm{kg}$ groups in physiologic variables before or after heparin administration, with the exception of ACT (Table 1). In the rFVIIatreated animals, the incidence of occlusion of vein grafts and arterial anastomoses was significantly higher than in the placebo group (vein $87.5 \%$ rFVIIa vs $12.5 \%$ placebo; artery $87.5 \%$ rFVIIa vs $25 \%$ placebo; $P<.05$ for both). The average vein graft diameter $(0.40 \pm 0.13 \mathrm{~cm})$, carotid artery diameter $(0.15 \pm 0.02 \mathrm{~cm})$, and graft flow per patent graft $(34.9 \pm 8.0 \mathrm{~mL} / \mathrm{min})$ were similar to those in protocol 1.

TABLE 2. Vascular graft characteristics

\begin{tabular}{lcccc}
\hline rFVIIa dose & $\begin{array}{c}\text { Vein graft } \\
\text { diameter }(\mathbf{c m}) *\end{array}$ & $\begin{array}{c}\text { Carotid artery } \\
\text { diameter }(\mathbf{c m}) *\end{array}$ & $\begin{array}{c}\text { Average graft } \\
\text { flow }(\mathbf{m L} / \mathbf{m i n}) *\end{array}$ & $\begin{array}{c}\text { Graft flow per patent } \\
\text { graft }(\mathbf{m L} / \mathbf{m i n}) \dagger\end{array}$ \\
\hline Placebo & $0.38 \pm 0.05$ & $0.14 \pm 0.02$ & $32.5 \pm 13.8$ & $34.7 \pm 11.2$ \\
$20 \mu \mathrm{g} / \mathrm{kg}$ & $0.40 \pm 0.05$ & $0.14 \pm 0.02$ & $29.4 \pm 16.8$ & $36.1 \pm 9.4$ \\
$90 \mu \mathrm{g} / \mathrm{kg}$ & $0.39 \pm 0.06$ & $0.14 \pm 0.02$ & $20.6 \pm 20.8$ & $35.4 \pm 13.7$ \\
$300 \mu \mathrm{g} / \mathrm{kg}$ & $0.38 \pm 0.07$ & $0.14 \pm 0.02$ & $1.8 \pm 7.2 \ddagger$ & 28.5 \\
\hline
\end{tabular}

$r F V I I a$, Recombinant factor VIIa. ${ }^{\mathrm{n}} \mathrm{n}=16$ per group except for placebo $(\mathrm{n}=15)$ and $90 \mu \mathrm{g} / \mathrm{kg}(\mathrm{n}=12) . \dagger$ Number of patent grafts per group is placebo $=15,20 \mu \mathrm{g} / \mathrm{kg}=13,90 \mu \mathrm{g} /$ $\mathrm{kg}=7$, and $300 \mu \mathrm{g} / \mathrm{kg}=1 . \ddagger P<.05$ compared with placebo at the same time point. 


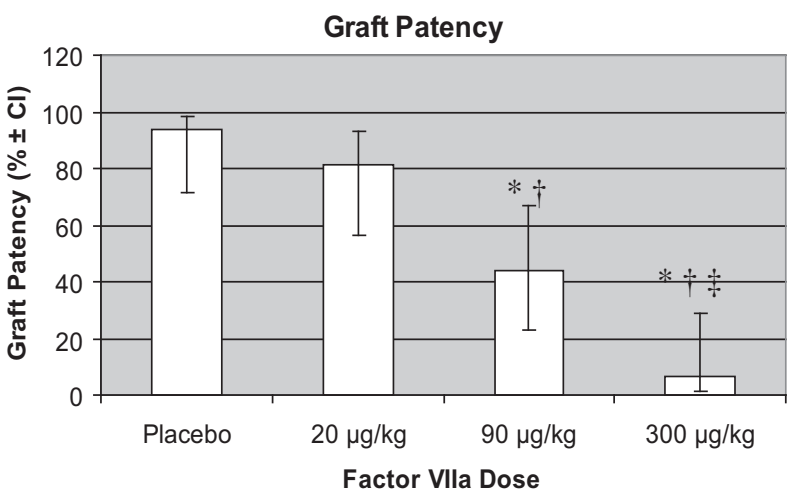

FIGURE 1. Vein graft patency (defined as number of grafts patent/total number of grafts*100) was significantly reduced in a dose-dependent fashion after rFVIIa. $* P<.05$ compared with placebo. $\dagger P<.05$ compared with $20 \mu / \mathrm{kg}$. $\ddagger P<.05$ compared with $90 \mu / \mathrm{kg}$. $C I, 95 \%$ Confidence interval.

\section{DISCUSSION}

This study demonstrates that administration of rFVIIa was associated with increased thrombosis and decreased graft patency in a rabbit model of fresh vascular anastomoses. A clear dose response was observed, with an inverse relationship between vascular graft patency and rFVIIa dose and serum drug levels. The lowest dose of rFVIIa $(20 \mu \mathrm{g} / \mathrm{kg})$ did not result in a significant increase in graft occlusion relative to placebo controls in this model. At the highest dose $(300 \mu \mathrm{g} / \mathrm{kg})$, both venous grafts and simple end-to-end arterial anastomoses experienced a similar degree of occlusion, suggesting that the thrombotic effect was independent of the type of anastomosis. The range of rFVIIa doses used in this study encompasses the range of doses administered clinically for patients with hemophilia $(90 \mu \mathrm{g} / \mathrm{kg}){ }^{6}$ patients undergoing cardiac surgery (11-180 $\mu \mathrm{g} / \mathrm{kg}){ }^{3}$ and patients with trauma. ${ }^{11}$ Our results suggest that higher doses of rFVIIa may detrimentally influence

\section{Plasma Factor VII Levels}

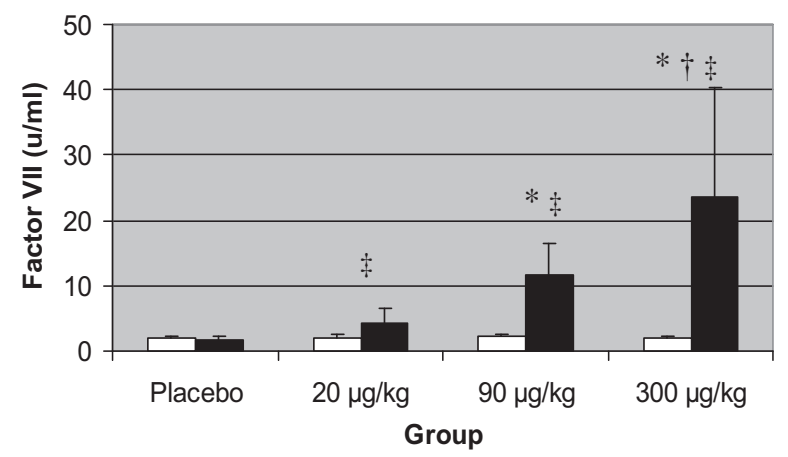

口Factor VII Levels (Baseline) \Factor VII Levels (Post-Dose)

FIGURE 2. Plasma factor VII activity levels increased significantly after 1 of 3 doses of rFVIIa. $* P<.05$ compared with placebo at the same time point. $\dagger P<.05$ compared with $20 \mu \mathrm{g} / \mathrm{kg}$ and $90 \mu \mathrm{g} / \mathrm{kg}$ at the same time point. $\ddagger P<.05$ compared with baseline value. graft patency, and therefore, if rFVIIa is administered to secure hemostasis in patients with new vascular anastomoses, the lowest effective dose should be given. Furthermore, clinical safety evaluations of rFVIIa in patients with cardiovascular disease should include a range of doses and assessment of graft patency.

Use of recombinant FVIIa has been reported in a variety of cardiovascular surgical settings, predominantly as case reports or case-cohort studies. In most of these studies, a reduction in postoperative bleeding was reported in patients with intractable blood loss who received rFVIIa. However, the total number of cases of rFVIIa use in cardiac surgery is still relatively small. For example, the first randomized placebo-controlled trial that assessed rFVIIa in cardiac surgery treated only 10 patients with $\mathrm{rFVIIa}(90 \mu \mathrm{g} / \mathrm{kg}) .{ }^{1}$ In this study, the transfusion requirements were significantly reduced with $\mathrm{rFVIIa}$, but vascular graft patency was not assessed. The CRAFT study of more than 500 patients undergoing cardiac surgery in Canada showed a reduction in median allogeneic red blood cell unit transfusions from 8 to 2 units after rVIIa treatment. ${ }^{4}$ Although the morbidity and mortality rates were greater than $30 \%$, this was thought to be within the range expected from a separate cohort of comparable non-rVIIa-treated patients. Predictors of complications were preoperative hemodynamic instability and red blood cell transfusion, and predictors of nonresponse to rVIIa were pretreatment coagulopathy and massive transfusion. A recently reported randomized clinical trial of rVIIa in 172 patients bleeding after cardiac surgery found a significantly reduced requirement for reoperation or allogeneic blood products, and a higher incidence of critical serious adverse events, including stroke, with rVIIa treatment. ${ }^{5}$ Doses as low as 11 to $21 \mu \mathrm{g} / \mathrm{kg}$ have also been used to treat bleeding in cardiac surgical patients. ${ }^{3}$ Recent guideline documents have suggested a weak recommendation, based on low-quality evidence, for the use of rFVIIa as rescue therapy for select patients with refractory hemorrhage unresponsive to standard hemostatic therapies. ${ }^{12-14}$

The mechanism by which rFVIIa promotes hemostasis at the site of fresh vascular anastomoses and injury is likely due to enhanced local thrombin generation from activated platelets and to direct activation of Factor $\mathrm{X}$ after complexing with tissue factor at the site of injury. ${ }^{15}$ Such a mechanism may have also contributed to rFVIIa-mediated thrombosis in a rabbit model of vascular injury to the common carotid artery. ${ }^{16}$ In addition to concerns about formation of thrombus at fresh vascular anastomotic sites, there is also laboratory and clinical evidence to suggest that rFVIIa may also promote occlusion of nonatherosclerotic vessels. In clinical trials that assessed rFVIIa, a significantly higher incidence of remote arterial thromboses was observed in patients who received rFVIIa for intracerebral hemorrhage ${ }^{17}$ or cardiac surgery. ${ }^{18,19}$ In a recent review of randomized clinical trials, arterial thromboembolic events were reported to occur more frequently with rFVIIa use. ${ }^{19}$ The majority were coronary 
ischemic events, occurring 2.4 times more frequently in rFVIIa-treated patients. ${ }^{19}$ Elevated factor VIIa levels have been associated with retinal vein occlusion. ${ }^{20}$ In another analysis of thromboembolic events with rFVIIa administration that were reported to the Food and Drug Administration, arterial thromboses (eg, myocardial infarction and stroke) also accounted for the largest number. ${ }^{21}$ Death was thought to be related to thromboembolic events in over half of the cases, supporting the clinical severity of these events. ${ }^{21}$ Although the total number of reported thrombotic adverse events related to rFVIIa might be felt to be low, it is possible that many more have gone unreported. Our results suggest that safety evaluations of future clinical studies of rFVIIa in patients with cardiovascular disease should include specific assessment of graft patency. Myocardial infarction may not be an adequate surrogate measure of graft patency because not all thrombosed grafts result in acute myocardial infarction. The need for adequate clinical studies to assess drug safety is emphasized by the current controversy regarding the safety of aprotinin. ${ }^{7,8}$ As in other examples, the sample size required to demonstrate efficacy is often smaller than that required to demonstrate safety.

The model used for these experiments was adapted from an established model of vein graft maturation and was chosen because of the similarity in vessel size to human coronaries. There are many factors that can contribute to thrombosis formation and early graft failure. The harvesting process can cause tissue factor expression, fibrin deposition, platelet and neutrophil adherence, and decreased tissue plasminogen production. ${ }^{22}$ Vein grafts have been shown to have decreased thrombomodulin activity, nitric oxide, and prostacyclin, which enhance local thrombin generation and platelet activation, thus predisposing to early graft failure. ${ }^{23}$ Addition of rFVIIa to this potentially thrombogenic environment could add to the likelihood of subsequent graft failure.

This study has some important potential limitations, including the number of animals used, relevance to human vascular physiology, lack of clinical data, and use of only 1 time point for investigation. Although this is the largest animal study of graft patency with rFVIIa, because of the sample size and dosing regimen used, we cannot make conclusions about intermediate doses (between 20 and $90 \mu \mathrm{g} / \mathrm{kg}$ ). We intentionally limited our observation period to 24 hours postoperatively because the manifestations of rFVIIa would likely be seen soon after its administration, and we wanted to avoid other confounding factors. Our experiments involved a recombinant human protein infused into rabbits, but human factor VII is similar to many other species in its primary amino acid sequence, domain organization, 3-dimensional structure, and reaction with anti-factor VII antisera. ${ }^{24}$ Rabbits have been used in the early development of activated factor VII, and to demonstrate that it is hemostatically effective, ${ }^{25}$ that it does not cause systemic activation of the coagulation system, and to evaluate the efficacy of rFVIIa in various bleeding syndromes. ${ }^{26}$ In addition, we chose this model because it has been used to study relevant atherosclerotic processes, such as restenosis, and the arterial and graft sizes approximate those in human coronary arteries. However, unlike some patients, these animals did not have microvascular bleeding related to exposure to cardiopulmonary bypass or oral antihemostatic agents, such as aspirin or clopidogrel. Nonetheless, a high proportion of patients with postoperative hemorrhage may have surgical bleeding and are not overtly coagulopathic. $^{27}$

\section{CONCLUSIONS}

This study suggests that high doses of rFVIIa (300 and 90 $\mu \mathrm{g} / \mathrm{kg}$ ) are associated with an increased incidence of occlusion of new vascular grafts. A clear dose-response effect was observed, suggesting that higher doses may be associated with increased thrombotic outcomes and that lower doses $(20 \mu \mathrm{g} / \mathrm{kg}$ ) may be safer for use in cardiovascular surgery. These findings require further validation in human subjects and may help guide the design of future studies and clinical use of rFVIIa.

The authors acknowledge the technical assistance of J. Colin Kay and Alana M. Harrington, and the generous donation of ACT supplies by Sorin Group Canada Inc.

\section{References}

1. Diprose P, Herbertson MJ, O'Shaughnessy D, Gill RS. Activated recombinant factor VII after cardiopulmonary bypass reduces allogeneic transfusion in complex non-coronary cardiac surgery: randomized double-blind placebo-controlled pilot study. Br J Anaesth. 2005;95:596-602.

2. Karkouti K, Beattie WS, Wijeysundera DN, Yau TM, McCluskey SA, Ghannam M, et al. Recombinant factor VIIa for intractable blood loss after cardiac surgery: a propensity score-matched case-control analysis. Transfusion. 2005;45:26-34.

3. Romagnoli S, Bevilacqua S, Gelsomino S, Pradella S, Ghilli L, Rostagno C, et al. Small-dose recombinant activated factor VII (NovoSeven) in cardiac surgery. Anesth Analg. 2006;102:1320-6.

4. Karkouti K, Beattie WS, Arellano R, Aye T, Bussieres JS, Callum JL, et al. Comprehensive Canadian review of the off-label use of recombinant activated Factor VII in cardiac surgery. Circulation. 2008;118:331-8.

5. Gill R, Herbertson M, Vuylsteke A, Olsen PS, von HC, Mythen M, et al. Safety and efficacy of recombinant activated factor VII: a randomized placebocontrolled trial in the setting of bleeding after cardiac surgery. Circulation. 2009; $120: 21-7$.

6. Hedner U, Erhardtsen E. Potential role for rFVIIa in transfusion medicine. Transfusion. 2002;42:114-24.

7. Mangano DT, Tudor IC, Dietzel C. The risk associated with aprotinin in cardiac surgery. N Engl J Med. 2006;354:353-65.

8. Fergusson DA, Hebert PC, Mazer CD, Fremes S, MacAdams C, Murkin JM, et al. A comparison of aprotinin and lysine analogues in high-risk cardiac surgery. N Engl J Med. 2008;358:2319-31.

9. Corwin HL, Gettinger A, Fabian TC, May A, Pearl RG, Heard S, et al. Efficacy and safety of epoetin alfa in critically ill patients. $N$ Engl J Med. 2007;357: 965-76.

10. Gill RW. Measurement of blood flow by ultrasound: accuracy and sources of error. Ultrasound Med Biol. 1985;11:625-41.

11. Boffard KD, Riou B, Warren B, Choong PI, Rizoli S, Rossaint R, et al. Recombinant factor VIIa as adjunctive therapy for bleeding control in severely injured trauma patients: two parallel randomized, placebo-controlled, double-blind clinical trials. J Trauma. 2005;59:8-15.

12. Ferraris VA, Ferraris SP, Saha SP, Hessel EA, Haan CK, Royston BD, et al. Perioperative blood transfusion and blood conservation in cardiac surgery: the 
Society of Thoracic Surgeons and The Society of Cardiovascular Anesthesiologists clinical practice guideline. Ann Thorac Surg. 2007;83(5 Suppl):S27-86.

13. Karkouti K, Beattie WS, Crowther MA, Callum JL, Chun R, Fremes SE, et al. The role of recombinant factor VIIa in on-pump cardiac surgery: proceedings of the Canadian Consensus Conference. Can J Anaesth. 2007;54:573-82.

14. Moltzan CJ, Anderson DA, Callum J, Fremes S, Hume H, Mazer CD, et al. The evidence for the use of recombinant factor VIIa in massive bleeding: development of a transfusion policy framework. Transfus Med. 2008;18:112-20.

15. Hedner U. Mechanism of action of factor VIIa in the treatment of coagulopathies. Semin Thromb Hemost. 2006;32(Suppl 1):77-85.

16. Charbonneau S, Girard F, Boudreault D, Ruel M, Blais N, Hardy JF. Recombinant human activated factor VII is thrombogenic in a rabbit model of cyclic flow reduction and does not reduce intra-abdominal bleeding. Thromb Haemost. 2007;97:296-303.

17. Mayer SA, Brun NC, Begtrup K, Broderick J, Davis S, Diringer MN, et al. Recombinant activated factor VII for acute intracerebral hemorrhage. $N$ Engl J Med. 2005;352:777-85.

18. Raivio P, Suojaranta-Ylinen R, Kuitunen AH. Recombinant factor VIIa in the treatment of postoperative hemorrhage after cardiac surgery. Ann Thorac Surg. 2005;80:66-71.

19. Levi M, Levy JH, Andersen HF, Truloff D. Safety of recombinant activated factor VII in randomized clinical trials. N Engl J Med. 2010;363:1791-800.
20. Kadayifcilar S, Ozatli D, Ozcebe O, Sener EC. Is activated factor VII associated with retinal vein occlusion? Br J Ophthalmol. 2001;85:1174-8.

21. O'Connell KA, Wood JJ, Wise RP, Lozier JN, Braun MM. Thromboembolic adverse events after use of recombinant human coagulation factor VIIa. JAMA. 2006;295:293-8.

22. Motwani JG, Topol EJ. Aortocoronary saphenous vein graft disease: pathogenesis, predisposition, and prevention. Circulation. 1998;97:916-31.

23. Kim AY, Walinsky PL, Kolodgie FD, Bian C, Sperry JL, Deming CB, et al. Early loss of thrombomodulin expression impairs vein graft thromboresistance: implications for vein graft failure. Circ Res. 2002;90:205-12.

24. Sheehan J, Templer M, Gregory M, Hanumanthaiah R, Troyer D, Phan T, et al Demonstration of the extrinsic coagulation pathway in teleostei: identification of zebrafish coagulation factor VII. Proc Natl Acad Sci U S A. 2001;98:8768-73.

25. Diness V, Bregengaard C, Erhardtsen E, Hedner U. Recombinant human factor VIIa (rFVIIa) in a rabbit stasis model. Thromb Res. 1992;67:233-41.

26. Hedner U, Ljundberg J, Lund-Hansen T. Comparison of the effect of plasmaderived and recombinant human FVIIa in vitro and in a rabbit model. Blood Coagul Fibrinolysis. 1990;1:145-51.

27. Hall TS, Brevetti GR, Skoultchi AJ, Sines JC, Gregory P, Spotnitz AJ. Re-exploration for hemorrhage following open heart surgery differentiation on the causes of bleeding and the impact on patient outcomes. Ann Thorac Cardiovasc Surg. 2001;7:352-7. 